\title{
Informed patient choice in treatment abroad - A response to recent commentaries
}

\author{
Eszter Kovacs*, Gabor Szocska
}

\author{
*Correspondence to: Eszter Kovacs, Email: kovacs.eszter@emk.sote.hu \\ Copyright: $\odot 2015$ by Kerman University of Medical Sciences \\ Citation: Kovacs E, Szocska G. Informed patient choice in treatment abroad - A \\ response to recent commentaries. Int J Health Policy Manag. 2015;4(7):491-492. \\ doi:10.15171/ijhpm.2015.86 \\ Received: 1 April 2015, Accepted: 16 April 2015, ePublished: 19 April 2015
}

\section{$\mathrm{L}$} unt (1) and Mainil (2) emphasize the importance of continued research into the scope, nature and motivations for cross border care within Europe. Understanding patient mobility in the rapidly changing environment and turbulent movements is crucial in the consideration of accessible healthcare provision. Crossing the border or travelling far destinations in order to obtain healthcare, medical services and wellness, spa and relaxation treatments is not a new phenomenon. Europe-wide and global patient flows have been doubtlessly growing in the last few decades. Our study highlights motivations of a sample of predominantly Romanian patients travelling to Hungary for care in the context of a stable and longstanding between these two EU countries - also to note that significant amount of Romanian patients having had sought treatment abroad on several occasions - not exclusively in Hungary - and aiming to return home in improved health condition. More frequent drivers for patient mobility were perceptions of better quality of care, access to specialist care, and shorter waiting times. Previous studies $(3,4)$ have also suggested that one of the most important drivers of patient mobility is the greater affordability of different treatments abroad. When considering the price differences, that should also be highlighted that surrounding neighbouring countries might have similar prices and easier for them to get reimbursed by domestic health insurer than those patients travelling from longer distances. In Romania, private provision, consumer-driven demand and market-driven elements play a dominant role (5). On the other hand, the trends in health spending of the population for health protection and healthy lifestyle show increase globally, patients/clients tend to invest more into their health and any health-related activities. Our study echoes recent research which also found that important motivations were avoidance of waiting lists, experiences of poor health services and quality, and lack of access specialists or advanced technology (6). In addition, there is increasing literature on patient mobility trends to combine medical care with leisure and cultural programs $(7,8)$.

Lunt (1) and Mainil (2) have also captured the existing tension between the importance of strengthening national health systems and allowing for safe, high-quality cross-border care, as supported by the most recent European patient directive
(9). Our study reflects other research on the limitations of healthcare systems, e.g. distrust or disorganisation in the local healthcare system (10), as important drivers for seeking care abroad. Lack of access to certain specialties in the health workforce is one of the main challenges in Romania. Many health professionals emigrate and are likely to work abroad for longer periods - also Hungarian professionals practicing part-time in Romania -, which is likely to cause a shortfall in availability of the domestic health workforce (11), warranting a renewed focus on achieving the right balance of workforce mix, skill-mix and substitution (12).

Another emerging area of research is the shifting attitudes of patients to healthcare (GFK Hungary 2012): individual healthcare behaviours and health consumption are altering due to increased health literacy, easy access to health information and the priority of health as a value among certain populations. Moreover technological development - e-health, m-health - has supported an increased focus on patient-centred care and a shifting doctor-patient relationship, away from hierarchal interaction and toward a more informed, empowered and proactive patient. The patient is rather a client, a customer who is responsible for his health and enrols services besides health prevention and alternative medicine. Therefore, there is a new paradigm where health experience becomes commonly preferred by the new healthcare customer, international patients, medical tourists are very likely to belong to those groups, where medical service use, health practices and intention for improved health is more common.

In conclusion, we agree with Lunt (1) and Mainil (2) that more research needs to be conducted to assess the 'precise flows and drivers' - migration potential, intention to travel abroad based on the free movement of goods, services and professionals - and the broader behavioral aspects of cross border care and that the development of conceptual models on mobile health systems and their users can help do so.

\section{Ethical issues \\ Not applicable.}

Competing interests

Authors declare that they have no competing interests.

\section{Authors' contributions}

EK prepared the response text, literature check and GS provided final inputs and revision for the manuscript.

\section{References}

1. Lunt N. International Patients on Operation Vacation: Medical Refuge and Health System Crisis; Comment on "International 
Patients on Operation Vacation - Perspectives of Patients Travelling to Hungary for Orthopaedic Treatments". Int J Health Policy Manag 2015; 4: 323-5. doi: 10.15171/ijhpm.2015.56

2. Mainil T. Medical sociology as a heuristic instrument for medical tourism and cross-border healthcare: Comment on "International patients on operation vacation - perspectives of patients travelling to Hungary for orthopedic treatments". Int $\mathrm{J}$ Health Policy Manag 2015; 4: 243-4. doi: 10.15171/ijhpm.2015.37

3. Wismar M, Palm W, Figueras J, Ernst K, van Ginneken E, editors. Cross-border health care in the European Union. Mapping and analysing practices and policies. European Observatory on Health Systems and Policies; 2011.

4. McMahon D. Medical tourism and cross-border care. Background paper. Toronto: Nuffield Council on Bioethics; 2013.

5. Vla descu C, Scîntee G, Olsavszky V. Romania - Health system review. The European Observatory on Health Systems and Policies; 2008. Health Systems in Transition; vol 10.

6. Klar A. Gesundheitstourismus in Europa - Eine empirische Transaktionskosten-Analyse. Budapest: Andrássy Universität; 2013. p. 287.

7. Wagner C. Moser F, Hohn A, Dobrick K, Verheyen F. Europabefragung 2012: Geplante grenzüberschreitende
Versorgung in der EU Ärzte und Zahnärzte aus Sicht der TKVersicherten. WINEG Wissen; 2013.

8. Kovacs E, Szocska G. 'Vacation for your teeth' - Dental tourists in Hungary from the perspective of Hungarian dentists. Br Dent J 2013; 215: 415-8. doi: 10.1038/sj.bdj.2013.995

9. European Parliament and Council. Directive 2011/24/EU of the European Parliament and of the Council of 9 March 2011 on the application of patients' rights in cross-border healthcare. Available from: http://eur-lex.europa.eu/LexUriServ/LexUriServ. do?uri=OJ:L:2011:088:0045:0065:EN:PDF

10. Crooks VA, Li N, Snyder J, Dharamsi S, Benjaminy S, Jacob KJ, et al. "You don't want to lose that trust that you've built with this patient...": (Dis)trust, medical tourism, and the Canadian family physician-patient relationship. BMC Fam Pract 2015; 16: 1. doi: 10.1186/s12875-015-0245-6

11. Ognyanova D, Maier CB, Wismar M, Girasek E, Busse R. Mobility of health professionals pre and post 2004 and 2007 EU enlargements: Evidence from the EU project PROMeTHEUS. Health Policy 2012; 108: 122-32. doi: 10.1016/j. healthpol.2012.10.006

12. Sibbald B, Shen J, McBride A. Changing the skill-mix of the health care workforce. J Health Serv Res Policy 2004; 9: 28-38. 